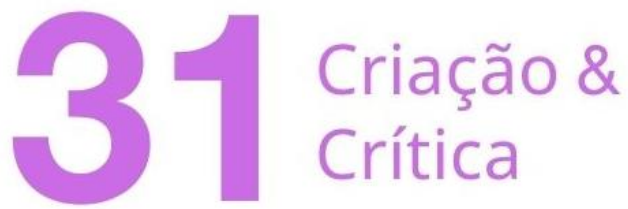

\section{UNA MIRADA DESDE LA ALCANTARILLA: UMA VERSÃO VOCAL DO POEMA HOMÔNIMO DE ALEJANDRA PIZARNIK}

Inés Terra Brandes ${ }^{1}$

RESUMO: Este artigo discorre sobre a peça Una mirada desde la alcantarilla, uma peça vocal criada a partir da leitura do poema homônimo da escritora argentina Alejandra Pizarnik (19361972) e apresentada como parte do terceiro capítulo "A voz como prática" na minha dissertação de mestrado. Este trabalho dá ênfase ao conhecimento da voz como um processo expandido de criação e aborda a leitura e a pesquisa vocal pela ótica da performance e da performatividade, valorizando a poesia como ponto de partida para a composição musical e realizando paralelos entre a noção de duplo como estratégia literária e o duplo como desdobramento do eu durante a exploração vocal. A escrita nômade de Pizarnik e a sua visão do corpo como um umbral (entre tipos de corporalidades diferentes) direcionam a pesquisa de sonoridades para a alternância de tipos de emissão vocal e ao mesmo tempo para a valorização de transições sutis entre vocalidades.

Palavras-Chaves: Alejandra Pizarnik, Duplo Literário, Exploração vocal, Performatividade Vocal, Máquina Performática, Corporalidade.

\section{UNA MIRADA DESDE LA ALCANTARILLA: A VOCAL VERSION OF ALEJANDRA PIZARNIK HOMONYMOUS POEM}

ABSTRACT: This article discusses the piece Una mirada de la Alcantarilla, a vocal piece created from the reading of the homonymous poem by Argentine writer Alejandra Pizarnik (1936-1972) and presented as part of the third chapter "Voice as practice" in my dissertation on master's degree. This work emphasizes the knowledge of voice as an expanded process of creation and approaches reading and voice research from the perspective of performance and performativity, valuing poetry as a starting point for musical composition and drawing parallels between the notion of double as a literary strategy and the double as an unfolding of the self during vocal exploration. Pizarnik's nomadic writing and her view of the body as a threshold (between different types of corporeality) direct sound research towards the alternation of types of vocal emission and, at the same time, towards the appreciation of subtle transitions between vocalities.

KeYwords: Alejandra Pizarnik, Literary Double, Vocal Exploration, Vocal Performativity, Performing Machine, Corporeality.

\footnotetext{
${ }^{1}$ Doutoranda na área de Processos de Criação Musical (Sonologia: criação e produção sonora) na Universidade de São Paulo. Graduada em Música Popular na Universidade Estadual de Campinas e mestre em Processos de Criação Musical. Idealizadora da série de performance vocal Língua Fora.
} 


\section{Criação \&}

\section{Alejandra Pizarnik e o poema Una mirada desde la alcantarilla}

Por mi sangre judía soy una exiliada. Por mi lugar de nacimiento, apenas si soy argentina (lo argentino es irreal y difuso). No tengo una patria. En cuanto al idioma, es otro conflicto ambiguo (GABRIELONI, 2013, p. 397).

Alejandra Pizarnik é uma escritora argentina nascida em 1936 em Avellaneda (município da região do grande Buenos Aires). De família judia oriunda da Rússia e com forte influência de autores como Artaud, Rimbaud e Lautréamont, seus trabalhos principais foram escritos nos gêneros de prosa e poesia. Entre a dor da inadaptação frente às demandas sociais ligadas à ideia de mulher da época, e um desejo não normativo, Pizarnik enfrenta-se com a morte e com as vozes estrondosas que gritam internamente. A escritora escreveu oito livros entre 1955 e 1971. O livro "Árbol de Diana"(1962) é o quarto livro de poemas da autora, escrito e lançado enquanto ela morava em Paris. Em 2018, a editora Relicário Edições publicou "Árvore de Diana" e "Os trabalhos e as noites", ambos com tradução de Davis Diniz. Há, também, uma edição prévia de uma versão bilíngue disponível na internet, publicada em 2017 pela editora Ellenismos, e traduzida por Nina Rizzi.

No livro "Árvore de Diana" encontra-se o poema Una mirada desde la alcantarilla:

23.

una mirada desde la alcantarilla

puede ser una visión del mundo

la rebelión consiste en mirar una

rosa

hasta pulverizarse los ojos

(PIZARNIK, 1962).

Tradução - versão I:

23.

um espreitar a partir da sarjeta

pode ser uma visão do mundo

a rebelião consiste em olhar uma

rosa

até pulverizar os olhos (DINIZ, 2018).

Tanto no livro "Árvore de Diana" como em outros textos de Pizarnik, a repetição da palavra mirada chama bastante a atenção. A repetição de palavras pode sugerir diferentes usos da mesma, segundo o contexto. Em entrevista realizada por Paulo Pires Fernandes com o tradutor do livro no Brasil Davis Diniz, ele explica:

Perceba que aí traduzimos a ideia de "mirar" ou "mirada" ora por espreitar, ora por olhar. A palavra "mirar" é muito comum no espanhol. 


\section{(3) Criação \&}

Pode ser tanto um olhar interpelativo quanto um olhar contemplativo. Em português, costumamos produzir variantes conforme o caso. A tarefa do tradutor é preservar (ou transcriar) os contextos de ambas as possibilidades. No caso do poema acima, optamos pelas variantes. No primeiro momento, trata-se de um tipo de olhar que vem a ser uma "visão do mundo". Estamos aí na espessura interpelativa do significante, percebe? Não é um olhar ingênuo; é um olhar ensaiado, por meio do qual o mundo passa a ter novos significados. Eis o princípio da poesia (DINIZ, 2017).

A escolha "Espreitar" para a palavra mirada acrescenta uma caracterização desse olhar que não se encontra dada de forma explícita no poema de Pizarnik. No entanto, é uma escolha instigante, já que apresenta um tipo de olhar atento, o olhar daquele que não é visto, o espião da realidade na busca por novos significados, como menciona Diniz. Alguém que se assoma, mas cuja perspectiva ainda é ignorada. Se a mirada inicial for preservada sem intenções definidas, há uma abertura maior para leituras possíveis, indicando que aquele olhar, que para Diniz pode ser lido como um olhar ingênuo por ser contemplativo, pode também possuir uma intenção ainda não revelada.

Tradução - Versão II:
uma olhada através do esgoto
pode ser uma visão do mundo
a rebelião consiste em olhar uma
rosa
até pulverizar os olhos (RIZZI, 2017).

Neste caso, Rizzi opta por uma tradução mais literal em relação à palavra original, mantendo o mesmo substantivo e a sonoridade final original da palavra: mirada por olhada. No entanto, o uso da palavra "olhada" em português parece se referir ao ato de olhar em si e não a um conceito mais complexo, como pode ser um tipo de perspectiva específica que envolve a elaboração de significados, mesmo que ainda não sejam revelados. Talvez o verbo substantivado se aproxime mais ao uso da mirada de Pizarnik. Na escolha da palavra esgoto, Rizzi abre outras possibilidades de interpretação para a produção de imagens durante a leitura, dirigindo a nossa atenção para o componente desse mundo subterrâneo no âmbito das cidades: a água contaminada. Por outro lado, ao substituir "a partir" por "através", a autora faz ênfase nesse mundo subterrâneo como uma espécie de lente.

Durante o processo de criação do solo vocal, ao pensar o poema em português, fiz outra versão para a primeira frase. O objeto Alcantarilla é o bueiro, a boca de lobo, o sumidouro. Entendo que sarjeta dá um significado mais amplo do que a palavra original alcantarilla. Apesar de existirem muitos tipos de alcantarillas, como falante nativa de espanhol, a imagem que visualizo a partir desta primeira frase é alguém no subterrâneo olhando através das diferentes linhas e barreiras do bueiro. Escolho através porque em português esta palavra se refere mais frequentemente ao tempo e não ao espaço. Vejo então dois tipos principais de alcantarillas: uma retangular que possui formato de grade, e outra redonda, mais parecida 


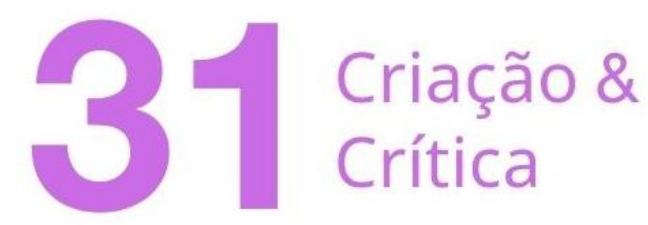

com uma tampa, com alguns buracos redondos por onde passa a água, e por onde é possível também enxergar com dificuldade. Nas duas imagens o campo de visão é extremamente limitado pelos traços deste objeto que tampa e cobre o que acontece no mundo subterrâneo.

Tradução - Versão III:

Um olhar através do bueiro

pode ser uma visão do mundo

A rebelião consiste em olhar uma

rosa

até pulverizar os olhos.

\section{A dimensão performática da leitura}

Ao ato de ler integra-se um desejo de restabelecer a unidade da performance, essa unidade perdida para nós, de restituir a plenitude por um exercício pessoal, a postura, o ritmo respiratório, pela imaginação. Esse esforço espontâneo, em vista da reconstituição da unidade, é inseparável da procura do prazer (ZUMTHOR, 2014, p. 66).

A pequena diferença na tradução da primeira frase do poema mostra como as imagens criadas por meio de diferentes corpos durante a leitura são imagens sempre situadas, ligadas à memória de cada leitora. "Não há verdade, é preciso repeti-lo ainda, vitalmente legítima, que não seja o particular. Porque só com ele o contato é possível. Por isso, porque ela é encontro, a leitura é diálogo" (ZUMTHOR, 2014). Por outro lado, há sempre na linguagem verbal uma falta no que se refere à variedade e especificidades do que é nomeado através da palavra. No livro de Adriana Cavarero "Vozes Plurais: Filosofia da Expressão Vocal (2011)", a autora cita o conto de Jorge Luis Borges "Funes, o memorioso" (1944) que apresenta uma personagem para quem "a função necessariamente generalizadora da linguagem era incompreensível" (CAVARERO, 2011), por evitar detalhes, especificidades e situações em relação ao que é nomeado. "Não satisfeito em denunciar a indevida redução dos diversos exemplares da espécie canina a um único substantivo, "aborrecia-o o fato de que o cão das três e catorze (visto de perfil) tivesse o mesmo nome do cão das três e quinze (visto de frente)" (CAVARERO, 2011). A elaboração singular de imagens durante a leitura evidencia que o incômodo aparentemente obsessivo de Funes faz bastante sentido. O processo de criação de imagens durante a leitura é um processo performático, por se tratar de uma relação entre as vozes e imagens propostas pela autora e o imaginário da leitora, e por ser um processo único em cada leitura, uma ação que embora seja direcionada sempre para o mesmo poema e as mesmas palavras, torna-se uma ação sempre diferente.

Segundo Paul Zumthor (2014), "a performance realiza, concretiza, faz passar algo que eu reconheço, da virtualidade à atualidade."A leitura é performativa porque provoca encontros entre corpos através da projeção de imagens e de vozes, por meio da fricção de significados e de signos. Ela é multisignificante, e portanto, decodificável" (FÉRAL, 2009). O evento é único porque ele é relacional. Se dá de modos diferentes porque as relações são 


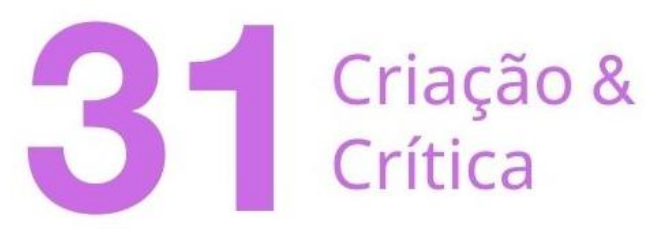

fluidas. "A performance não está em um lugar específico, mas é o entre "2" (SCHECHNER, 2002). "Meu corpo reage à materialidade do objeto, minha voz se mistura, virtualmente, à sua" (ZUMTHOR, 2014). Na percepção do poema embaralha-se o prazer da leitura com as imagens e discursos contidos nele. Nos poemas de Pizarnik a ideia de prazer dificilmente aparece como algo puro, entendendo que tudo gozo funde-se com a dor.

O medo, o sofrimento, a morte, não necessariamente aparecem com conotação negativa na obra de Pizarnik. São elementos frequentemente associados ao corpo, que, ao mesmo tempo que ameaçam, trazem uma sorte de refúgio ou morada, no interior desse discorrer semiótico que flerta com o caos $^{3}$ (PAMPÍN e BARBERO, 2015, p.6).

No artigo "Figuraciones de la corporalidad en Extracción de la piedra de locura de Alejandra Pizarnik"(2015), as autoras Ayelén Barbero e Ludmila Pampín apontam para a noção de corporalidade na poesia de Pizarnik, enfatizando uma contínua fragmentação e restauração do corpo. Segundo elas, na poética de Pizarnik há sempre uma representação de corpo associada à dor e outra ao gozo. Ao mesmo tempo, o corpo é continuamente abordado desde suas partes ou projetado temporariamente em outros objetos e imagens, desviando do eu lírico e mostrando que as verdades do corpo não são passíveis de cristalização. O caos do corpo é o que dá movimento à escrita, é o que faz possível a poética, mas ao mesmo tempo a problematiza, por mostrar o cansaço inevitável da incompletude da linguagem verbal. Um olhar subterrâneo pode ser um lugar, uma morada. Una mirada desde la alcantarilla puede ser una visión del mundo. Olhar a existência de uma rosa de maneira insistente pode ser um modo de se rebelar. La rebelión consiste en mirar una rosa. A destruição dos olhos pode ser a restauração de um outro corpo. Hasta pulverizarse los ojos.

\section{A máquina performática}

O olho percebe uma frase graficamente contorcida em forma de rosa: simultaneamente ele olha a flor e lê a frase. A percepção do texto se desdobra (ZUMTHOR, 2014, p. 72).

No livro "A máquina performática" (2019) os autores Gonzalo Aguilar e Mario Cámara discorrem sobre o campo experimental como o lugar não dividido em disciplinas e como um núcleo que possibilita a criação onde as relações se estabelecem de maneira inevitável, relações entre literatura, artes visuais, cinema e música. "O campo experimental seria essa máquina performática onde as ações não possuem campos impenetráveis, mas se encontram

\footnotetext{
${ }^{2}$ Tradução minha. Versão original:"Performance isn't in anything, but between" (SCHECHNER, 2002, p.30).

${ }^{3}$ Tradução minha. Original: "el miedo, el sufrimiento, la muerte, no necesariamente aparecen connotados negativamente en la obra de Pizarnik. Son elementos frecuentemente asociados a lo corporal, que, al mismo tiempo que amenazan, brindan una suerte de refugio o morada dentro de ese discurrir semiótico que coquetea con el caos" (PAMPÍN e BARBERO, 2015, p.6).
} 


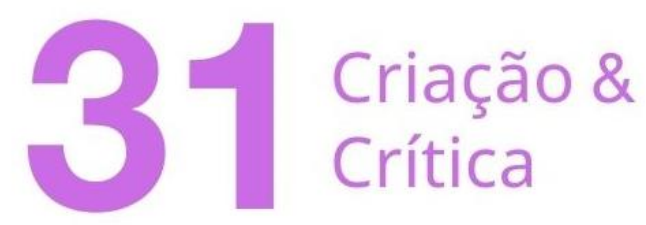

entrelaçadas desde a concepção de um poema, um filme, ou uma música"4 (AGUILAR e CÁMARA, 2019). "Não se trata da união entre áreas mas de "um campo de signos que provocam novos sensíveis" ${ }^{5}$ (AGUILAR e CÁMARA, 2019). Segundo os autores, o campo literário sofre ainda um processo de repressão por meio das instituições que delimitam a sua ação, privilegiando a letra escrita, limitando-a e afastando-a assim de outras interpretações. "A ideia é convocar à performance para mostrar que sua presença transforma as leituras possíveis de uma obra. Não é algo acessório ou ornamental: são as atualizações, as singularidades espaço-temporais que toda obra evoca, embora seja como ausência ou vão" 6 (AGUILAR e CÁMARA, 2019). A leitura seria então a constante atualização de uma obra, e suas possíveis vocalizações com novas constelações sonoras, tanto como poesia sonora que parte dos fonemas que o poema apresenta, como vocalidades que emergem no desdobramento dos sentidos do poema. Os autores abordam a literatura como ponto de partida desse campo experimental. Segundo eles:

A máquina performática é um dispositivo de horizontalidade. Como ponto de início, aplana a preeminência da textualidade, dos gêneros e das historicidades, partindo da premissa de que nenhum signo é mais importante do que outro. O campo experimental, resultado da máquina performática, se constitui como resultado de uma série de operações: abrir o texto a uma multiplicidade de ligações, e construir uma série que recupere signos ínfimos e inadvertidos. No campo experimental o que está em crise é a hegemonia textual como única fonte de autoridade, mas não a textualidade em si mesma. Ali os signos ingressam numa constelação que os despoja de suas marcas originais e permite construir novos sentidos transversais ${ }^{7}$ (AGUILAR e CÁMARA, 2019, p. 9).

No capítulo "Mapas acústicos e constelações sonoras", os autores traçam um panorama histórico sobre a dimensão performática do som vocal da literatura no Brasil, fazendo ênfase no grito, na glossolalia e no balbucio como expressões vocais que remetem

\footnotetext{
${ }^{4}$ Tradução minha. Original: "El campo experimental sería esa máquina performática donde las acciones no tienen campos impenetrables, pero se encuentran entrelazadas desde la concepción de un poema, una película, o una música" (AGUILAR e CÁMARA, 2019, p.12).

5 Tradução minha. Original: " un campo de signos que provocan nuevos sensibles" (AGUILAR e CÁMARA, 2019, p.12).

${ }^{6}$ Tradução minha. Original: La idea es convocar a la performance para mostrar que su presencia transforma las lecturas posibles de una obra. No es algo accesorio u ornamental: son las actualizaciones, las singularidades espacio-temporales que toda obra evoca, aunque sea como ausencia o hueco (AGUILAR e CÁMARA, 2019, p.9).

${ }^{7}$ Tradução minha. Original: "La máquina performática es un dispositivo de aplanamiento. Como punto de inicio, aplana la preeminencia de la textualidad, de los géneros y de las historicidades, partiendo de la premisa de que ningún signo es más importante que otro. El campo experimental, resultado de la máquina performática, se constituye como resultado de una serie de operaciones: abrir el texto a una multiplicidad de conexiones, y construir una serie que recupere signos ínfimos e inadvertidos. En el campo experimental lo que está en crisis es la hegemonía textual como única fuente de autoridad, pero no la textualidad en sí misma. Allí los signos ingresan en una constelación que los despoja de sus marcas originales y permite construir nuevos sentidos transversales (AGUILAR e CÁMARA, 2019, p. 9).
} 


\section{(3) Criação \&}

às urgências e pulsões dos corpos e à desestabilização do sentido. Para isto discorrem sobre a obra de poetas modernistas como Manuel Bandeira e Oswald de Andrade, sobre as interpretações posteriores das suas obras no Teatro Oficina, sobre o cinema de Glauber Rocha, e sobre a poesia concreta. Segundo Aguilar e Cámara, a poesia concreta tem se estudado pouco na sua perspectiva acústica, e muito mais na sua perspectiva gráfica e visual. "O poema concreto, utilizando o sistema fonético (dígitos) e uma sintaxe analógica, cria uma área linguística específica - "verbivocovisual" - que participa das vantagens da comunicação não verbal, sem abdicar das virtualidades da palavra"8 (AGUILAR e CÁMARA, 2019). Ao criar poemas que não apresentam uma linearidade discursiva e que sugerem imagens na maneira em que as letras ocupam o espaço numa folha ou em um fundo, os concretos apontam para uma linhagem conceitual não necessariamente baseada no significado das palavras na perspectiva sobre o que esses poemas podem dizer, e para uma problematização de como estes podem ser lidos, ditos e performados. "Com o poema concreto ocorre o fenômeno da metacomunicação: coincidência e simultaneidade da comunicação verbal e não verbal, com a nota de que se trata de uma comunicação de formas, de uma estrutura-conteúdo, não da usual comunicação de mensagens" (AGUILAR e CÁMARA, 2019).

Apesar do enorme leque de possibilidades que possui a exploração da dimensão acústica da voz nas interpretações durante a leitura de textos e na improvisação por meio das palavras, tomo a noção de máquina performática desde a perspectiva da exploração sonora como corporificação do poema. No processo da escrita de um poema há sempre uma escuta de sonoridades para além das palavras, imagens e projeções da ideia de corpo, segundo a biografia da autora. Nessa perspectiva, a leitura do poema é um ponto de partida para o desenvolvimento da peça vocal e para a exploração da performatividade da voz. O que proponho a partir do poema de Alejandra Pizarnik não é a experimentação vocal através da leitura da materialidade fonética do poema e os possíveis usos das palavras, sílabas e fonemas, mas é encarnar através do som vocal uma série de imagens propostas pela autora. O caminho realizado se dá através dos sentidos encontrados nessas imagens e no modo em que estes podem ser corporificados. Trata-se mais de uma tradução em cena do que de uma leitura literal da dimensão acústica das palavras contidas no poema. Através do poema penso em movimento vocal como projeções dos corpos fragmentados e restaurados por Pizarnik, e projeto espaços de ressonância para esses movimentos. Para melhor compreensão das reflexões elaboradas a partir desta peça, recomendo a audição da obra, disponível no link a seguir: <https://inesterra.bandcamp.com/album/una-mirada-desde-la- alcantarilla>

\section{Una mirada desde la alcantarilla como peça vocal}

Una mirada desde la alcantarilla (2016-2019) foi uma das primeiras peças inteiramente vocais que fiz. Ela possui duas datas de criação porque é uma peça que está

\footnotetext{
${ }^{8}$ Tradução minha. Original: "El poema concreto, usando el sistema fonético (dígitos) y una sintaxis analógica, crea un área lingüística específica -"verbivocovisual"- que participa de la ventajas de la comunicación no-verbal, sin abdicar de las virtualidades de la palabra" (AGUILAR e CÁMARA, 2019).

${ }^{9}$ Tradução minha. Original: "Con el poema concreto ocurre el fenómeno de la metacomunicación: coincidencia y simultaneidad de la comunicación verbal y no-verbal, con la nota de que se trata de una comunicación de formas, de una estructura-contenido, no de la usual comunicación de mensajes" (AGUILAR e CÁMARA, 2019).
} 


\section{Criação \&}

continuamente mudando seu formato, sendo inicialmente um solo vocal, porém apresentado também como uma vídeo performance e como dança. Neste texto comentarei a reflexão sobre a primeira versão, gravada em 2016. A peça tem duração de oito minutos e onze segundos e foi gravada por mim em estúdio caseiro.

\section{Sobre o processo de criação: encarnar um poema}

A peça vocal Una mirada desde la alcantarilla é um solo para voz desacompanhada. A noção de voz desacompanhada é parte das Notas sobre a voz ${ }^{10}$ (1976) publicadas na revista "The Painted Bride Quarterly" pela artista norte-americana Meredith Monk (Nova York, 1942) onde ela realiza uma descrição cronológica do seu trabalho vocal. Pode parecer redundante "um solo desacompanhado", mas considerando que no âmbito orquestral ou mesmo em instrumentações menores, seja em contextos de música escrita ou improvisada, pode haver "solos" entre partes da música onde os instrumentos possuem um protagonismo compartilhado, a noção de "solo" vem ressaltar a ideia do protagonismo do som vocal, porém em um contexto onde não há acompanhamento que estabeleça relações harmônicas e rítmicas preestabelecidas e tensionadas entre diferentes vozes. Não há arcabouço musical predeterminado. O arcabouço é o que emerge entre o poema e o corpo, e a condução do solo se dá pela relação desse corpo com o silêncio, após a leitura do poema.

Quando lemos um poema, projetamos imagens, paisagens, sons. Escutamos nossa própria voz na leitura. Escutamos outras vozes. O corpo se move. Ele se expande, se retrai. "Você pode ler não importa o quê, em qual posição, e os ritmos sanguíneos são afetados. É verdade que mal conceberíamos que, lendo em seu quarto, você se ponha a dançar, e, no entanto, a dança é o resultado normal da audição poética!" (ZUMTHOR, 2014). No artigo "Performances da oralitura: corpo, lugar de memória" (2003), fruto dos estudos direcionados para a performance e as cenas rituais afro-brasileiras, a pesquisadora Leda Martins lembra da importância das inscrições que se dão no corpo, como portal de sabedoria e de encontro de alteridades, por meio de uma memória que não prioriza a dimensão gráfica da letra escrita. A autora cita a raiz ntanga de uma das línguas bantu do Congo, a partir da qual se originam a palavra escrever e ao mesmo tempo a palavra dançar. Nessa perspectiva, o conhecimento se dá quando este passa pelo corpo. Pensar a leitura como um campo expandido é colocar a atenção nas escritas presentes no corpo, também por meio da escuta. Que sons há nos espaços do poema, nessas imagens, como esses sons ressoam no corpo? Ler pode ser então um modo de se deslocar, embora muitas vezes tentemos nos reconhecer nas leituras, desenhando aquilo que nos falta, mas que não necessariamente está no texto ou no poema.

Quando iniciei o processo de criação de Una mirada desde la alcantarilla (2016), fiz um roteiro de sonoridades a partir de imagens que o poema iluminou após algumas leituras. Marquei um ponto de partida e um ponto de chegada. Onde estou no poema? para onde vou? O que ficaria no meio seria esse olhar insistente (a mirada), uma textura em constante transformação apesar da sua tentativa de repetição. O ponto de partida seria a perspectiva daquele olhar desde o subterrâneo (a alcantarilla ou bueiro); uma existência que escuta e percebe o mundo desde o que está embaixo do asfalto. Esse primeiro som é um extremo grave, uma intenção do fundo da garganta, uma ação da faringe, um som produzido sem

${ }^{10}$ Original: Notes on the Voice. Solo for unaccompanied voice (Songs from the Hill). 


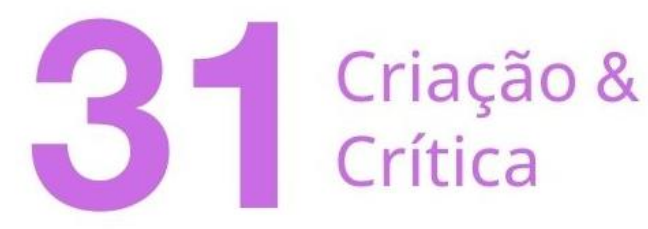

vibração de pregas vocais, um sopro grave que ressoa na terra. Na sequência da exploração desse som viriam os seus desdobramentos. Os desdobramentos na exploração vocal podem se pensar como desdobramentos do eu, duplos que se multiplicam, o eu lírico habitando diferentes corpos através de diferentes qualidades vocais. Por este motivo, cabe destacar que a parte do meio da peça vocal é a parte com mais variações texturais, melódicas e tipos de emissão vocal, podendo se modificar em cada apresentação da performance. Nessa parte há vários tipos de emissão vocal, como vibração com $R$ uvular, emissão coberta (com laringe abaixada e palato alto), drive, sons respiratórios com diferentes tipos de articulação na expiração, vibração de epiglote, sons nasais e estalos de língua simultâneos, entre outros.

O solo não é uma improvisação, porém a improvisação é um elemento fundamental durante a performance; como um modo de recriar no corpo os materiais que foram escolhidos e de descobrir outros novos entre estes, ligados à experiência do dia, às pessoas presentes e ao espaço que é gerado (BRANDES, 2019: p.134).

Ao pensar na produção vocal como uma relação entre os sistemas respiratório, fonatório e articulatório, pode-se estudar diferentes combinações desses sistemas por separado e acionar aos poucos as suas negociações como sistema integral. Nesse sentido, o caminho escolhido foi iniciar a exploração vocal fundindo as possibilidades do sistema articulatório e respiratório, articulando internamente na região epiglotal e uvular, para logo acrescentar a fonação com diferentes variantes e tipos de vibração, e finalmente revertê-la totalmente no último grito ingressivo da peça ${ }^{11}$. "A intenção de um olhar insistente sobre a imagem de uma rosa, para logo os olhos serem pulverizados conduziu o solo para um lugar de explosão, momento em que as sonoridades que foram apresentadas de maneira recursiva e continua, se desdobram em um som multifônico que se dissipa" (BRANDES, 2019).

Desde o início do processo faço várias versões de roteiros de sonoridades trabalhadas na peça. $O$ roteiro possui algumas descrições técnicas em relação ao lugar de articulação desses sons no trato vocal e outras indicações poéticas. As descrições técnicas provêm de símbolos e nomes fonéticos para algumas sonoridades vocais, que após produzidas reconheci no quadro fonético internacional ou IPA chart ${ }^{12}$. Há diversas vocalidades que ainda não consigo nomear, por fugirem do quadro descritivo, por entender também que se trata de fragmentos vocais que o autor Paul Zumthor chamaria de vocemas. "O vocema é um possível vocal. A lista de vocemas seria infinita, estamos definitivamente fora da fonologia clássica dos linguistas, para além das delimitações próprias das línguas naturais" (ZUMTHOR, 2014). Considerando isto seria preciso avaliar em exame otorrinolaringológico para saber com exatidão em quais estruturas são articuladas estas sonoridades, tanto as que foram aqui nomeadas a partir da minha experiência como cantora e professora, como as que não consigo nomear. Esse é um roteiro aproximado da produção vocal durante a peça. Para melhor entendimento do roteiro, segue uma ilustração do trato vocal (figura 1) e uma partitura gráfica da peça (figura 2).

${ }^{11}$ Sons vocais produzidos durante a inspiração.

${ }^{12}$ Disponível em <https://www.ipachart.com/> 


\section{Criação \&
Crítica}

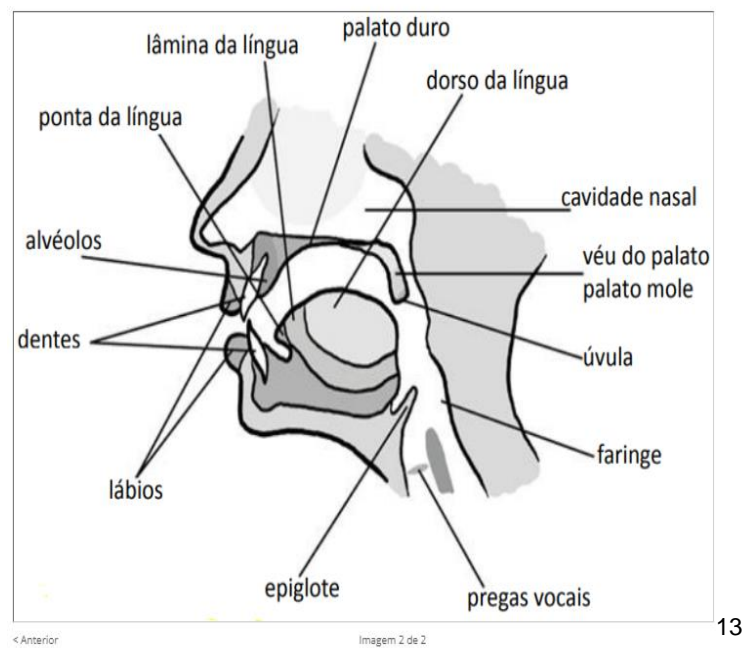

(Figura 1)

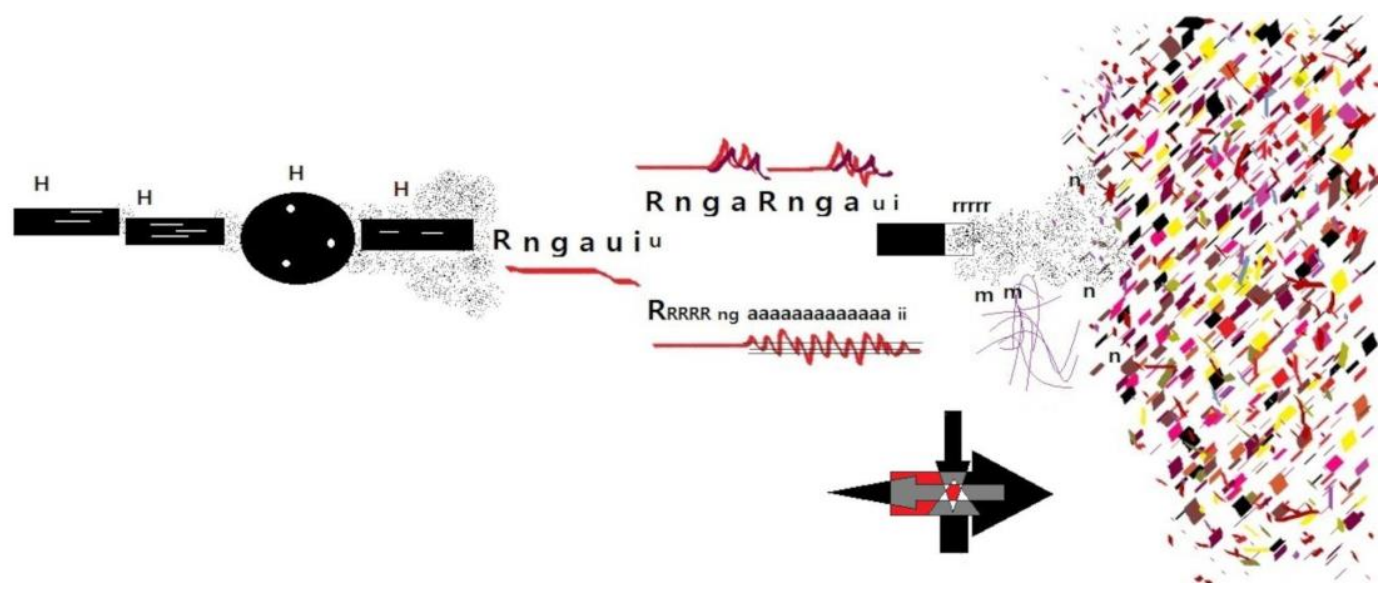

(Figura 2)

$\mathrm{Na}$ partitura gráfica, os blocos pretos retangulares e o bloco oval remetem à continuidade da perspectiva do olhar desde o bueiro. Neles há pequenas frestas que permitem algum tipo de visão. $\mathrm{O}[\mathrm{H}]$ é o símbolo fonético para o som grave não vozeado (sem vibração de pregas vocais) inicial. $O[R]$ é o símbolo fonético para um tipo de "r" que é articulado na região uvular do trato vocal, região mais próxima da faringe. A articulação do $R$ é ligada ao $n$ (nasalidade) e logo às vogais $a, u, i$ e novamente $u$, em um glissando ${ }^{14}$ descendente. $A$ combinação de flechas se refere aos tipos de emissão vocal em direções diferentes: tanto ingressivas (produzidas durante a inspiração), como egressivas (produzidas durante a expiração). O desenho de linhas vermelhas em formato de ondas sonoras representa os diversos desdobramentos da combinação do "r" uvular com a nasalidade, nos diferentes vibratos e texturas que aparecem ao longo da peça. A onda riscada ilustra o drive junto com o vibrato de epiglote. O preto esfumado marca seções onde há presença de acúmulo de saliva ou de emissão com bastante ar. Os fragmentos coloridos que se expandem representam o

\footnotetext{
${ }^{13}$ Disponível em: <https://petletras.paginas.ufsc.br/2020/10/27/voce-conhece-o-alfabeto-ipa/>

${ }^{14}$ Efeito de transição de uma frequência para a outra, deslizando pelas frequências entre estas duas.
} 


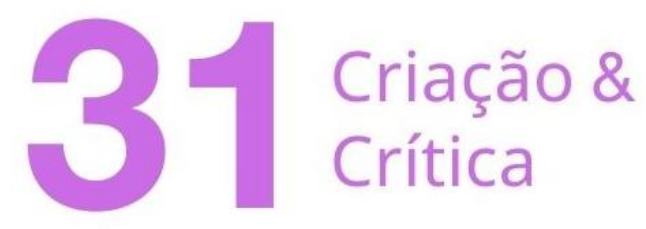

último grito ingressivo e multifônico onde há inúmeros desdobramentos das sonoridades que são apresentadas ao longo da peça. Ao mesmo tempo que aparecem como fragmentos, restauram o corpo desenhando uma nova forma.

\section{Roteiro de sonoridades:}

- A perspectiva do olhar: $[\mathrm{H}]$ epiglotal não vozeado fricativo ${ }^{15}$. Pequenas modificações do trato vocal a partir desta sonoridade grave. Sons sem vibração de pregas vocais: 1) ronco: inspiração simultânea pela boca e pelo nariz articulando na região uvular ${ }^{16}$.

2) Sons respiratórios contínuos com acumulação de saliva ${ }^{17}$.

- Duplos ou "o olhar se transformando na sua insistência":

- Sons egressivos ${ }^{18}$ com vibração de pregas vocais: transição da articulação epiglotal $[\mathrm{H}]$ não vozeada ao ataque do $[\mathrm{R}]$ uvular vozeado ${ }^{19}+$ nasalidade $^{20}+$ $\mathrm{G}+$ glissando descendente $(\mathrm{a}+\mathrm{u}+\mathrm{i}+\mathrm{u})$. Segunda versão: $\mathrm{R}$ uvular + nasalidade + vibrato de epiglote ${ }^{21}+$ drive $^{22}$.

- Volta da sonoridade inicial da perspectiva - Glossolalia. Acúmulo de saliva com R uvular. ${ }^{23} r$ alveolar não vozeado (sem vibração de pregas vocais). ${ }^{24}$

- Nasalidade (m) - Novidade na transformação do olhar - alternância de sons ingressivos e egressivos. ${ }^{25}$

- Nasalidade e movimento de palato mole ${ }^{26}$. Nasalidade + drive com vibração de epiglote $^{27}$.

- Retorno à perspectiva do olhar inicial.

- Sons respiratórios com fonação suave ingressiva e egressiva ${ }^{28}$. Nasalidade - vibrato de epiglote + drive.

- Vibração nasal contínua com sons de estalos de língua simultâneos ${ }^{29}$.

- Olhos pulverizam ou um grito ingressivo - o grito em direção ao próprio corpo ${ }^{30}$.

${ }^{15}$ De 00:00 a 00:55, de 00:59 a 01:30, de 03:48 a 04:13, de 05:44 a 05:59.

${ }^{16}$ De 00:56 a 00:58.

${ }^{17}$ De 01:31 a 02:18.

${ }^{18}$ sons vocais produzidos durante a expiração.

${ }^{19}$ De 02:19 a 2:21, de 2:38 a 2:40, de 03:25 a 03:33.

${ }^{20}$ De 0:21 a 0:24.

${ }^{21}$ De 02:56 a 02:57, de 0:58 a 0:59, 03:09 a 03:10, 03:12, 03:14.

${ }^{22}$ De 03:15 a 03:22, de 03:34 a 03:44.

${ }^{23}$ De 04:18 a 04:21.

${ }^{24}$ De 04:22 a 04:29.

${ }^{25}$ De 04:33 a 05:00.

${ }^{26}$ De 05:01 a 05:16.

${ }^{27}$ De 05:21 a 05:38.

${ }^{28}$ De 06:00 a 06:16.

${ }^{29}$ De 06:55 a 07:02.

${ }^{30}$ De 07:47 a 08:11. 


\section{Criação \&}

\section{Duplo literário e duplo vocal}

A árvore, na coleção de poemas, simboliza a unidade e a síntese do eu; Embora essa mesma árvore, o eixo condutor, possa sofrer a ruptura de sua unidade, como ocorre com o sujeito poético, sua regeneração, a formação de si também é possível ${ }^{31}$ (TORRES, 2017).

Assim como acontece na prosa e no romance, na poesia a ambiguidade do eu enunciativo é frequente; na elaboração de uma persona, assumindo certa ficcionalidade, na escolha da enunciação por meio da segunda ou terceira pessoa, na escolha de um desdobramento através de um outro alguém ou através de objetos e imagens, como o símbolo do espelho ou do barco saindo do próprio corpo. Segundo a autora Matilde B. Escobar Negri (2014), na poesia de Pizarnik a estratégia de deslocamento do eu lírico propõe uma problematização da noção de unicidade identitária do sujeito enunciativo.

O duplo, seja como uma materialização exterior similar ou como algum aspecto psíquico desdobrado, origina uma alteração da percepção de certa unicidade identitária, que coloca em evidência o diferente a si mesmo. Esta diferença de si se manifesta como uma contingência para o sujeito, além de se apresentar como uma experiência que o aparta da estabilidade do "eu sou"32 (NEGRI, 2014, p. 133).

A contingência de habitar outro corpo, de ser habitada e de se projetar em um objeto é um medo e um desejo constante no livro Árvore de Diana. Partió de mi un barco llevándome. Alguna vez tal vez me iré sin quedarme ${ }^{33}$. "Miedo de ser dos /camino del espejo: / alguien en mí dormido / me come y me bebe. ${ }^{34}$ Sabios animales nostálgicos visitaban su cuerpo caliente. ${ }^{35}$ Cuando vea los ojos que tengo en los míos tatuados ${ }^{36}$. Algo quer fugir de si, de uma leitura fixa da unicidade, para forjar a diferença. Falar de si como se fosse outra. Escrever para sair de si ou para conviver com diferentes versões de si mesmo. Versão animal, versão barco, versão tatuagem, versão sonho, sombra, resto. Inventar outras ficções para a existência do mesmo corpo.

Essa mesma instabilidade e ou ambiguidade enunciativa é a que dá passo e abre a possibilidade de considerar a intervenção de duplos do

\footnotetext{
${ }^{31}$ Tradução minha. Original: (...), el árbol, en el poemario, simboliza la unidad y la síntesis del yo; aunque ese mismo árbol, eje rector, puede padecer la ruptura de su unidad, tal como ocurre con el sujeto poético, también es posible su regeneración, la formación del yo (TORRES, 2017).

${ }^{32}$ Tradução minha. Original:.. el doble, ya sea como una materialización exterior similar o como algún aspecto síquico desdoblado, origina una alteración de la percepción de cierta unicidad identitaria, que pone en evidencia lo diferente a sí mismo. Esta diferencia de sí se manifiesta como una contingencia para el sujeto, además de presentarse como una experiencia que lo aparta de la stasis del "yo soy" (NEGRI, 2014, p.133).

${ }^{33}$ Poema número 33 do livro Árbol de Diana (1962).

${ }^{34}$ Poema número 8 do livro Árbol de Diana (1962).

${ }^{35}$ Poema número 34 do livro Árbol de Diana (1962).

${ }^{36}$ Poema número 19 do livro Árbol de Diana (1962).
} 


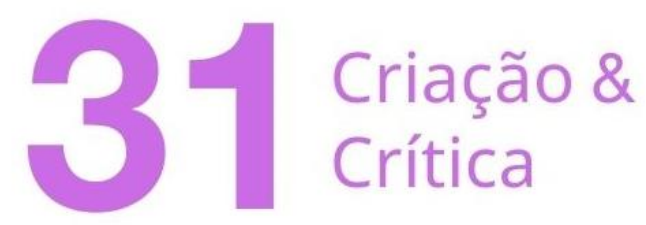

sujeito enunciativo, já que, como tem se apontado, mostra-se um desprendimento que poderia abrir espaços para a convivência de distintas vozes alternantes interactuando, "estruturadas" como sequências onde há silêncio e ocultamento ou palavra e revelação ${ }^{37}$ (NEGRI, 2014, p. 134).

O que seria então um duplo vocal? Que paralelos posso traçar entre a escrita de um poema e a exploração vocal? Para isto parece mais acertado focar a atenção não só na percepção posterior das obras, uma vez que o texto está no papel, uma vez que a voz foi gravada, mas principalmente no processo de escrita e no processo da exploração vocal. Nos dois casos há a projeção de uma voz ou de várias vozes. Negri (2014), por meio de Rodriguez (2009) explica que o duplo na literatura acontece por meio do pacto lírico:

entendido como um pacto discursivo no qual toma-se a dimensão de um sujeito corporal em relação com seu entorno e seu universo afetivo (Rodriguez, 2009), assume que esse sujeito enunciador não necessariamente responde a um sujeito real, senão que pode surgir como uma construção ficcional de um eu enunciativo no poema (NEGRI, 2014, p. 131) ${ }^{38}$.

Este pacto inaugura um campo semiótico para quem lê. Apesar do pacto se dar a partir da intenção da escritora, haverá sempre tensões entre o que é proposto e o que é percebido. Na exploração vocal esse pacto é tácito, continuamente atualizado e composto pelo que se espera de um determinado corpo enquanto voz em situações como a leitura de um poema, a poesia sonora, o free jazz, a improvisação livre, a composição de obras abertas. Ao mesmo tempo, tanto na projeção da voz na escrita como na exploração vocal pode-se apresentar uma junção de temporalidades, diferentes versões da voz que emana do corpo: uma voz da infância, uma voz que remete a uma perda recente, uma voz escutada pela primeira vez por um movimento articulatório acidental. O duplo aqui aparece como uma encruzilhada de experiências do corpo. Isto fica explícito, segundo Negri (2014), no poema número 11 da "Árvore de Diana": Yo y la que fui nos sentamos / en el umbral de mi mirada. Na peça vocal Una mirada desde la alcantarilla há uma alternância entre sons egressivos e ingressivos. Entendo esta variação como uma constante mudança entre sons em direção ao próprio corpo, emitidos durante a inspiração, e sons em direção aos desdobramentos desse corpo. Os dois caminhos estão continuamente sendo influenciados um pelo outro.

\footnotetext{
${ }^{37}$ Tradução minha. Original: Esa misma inestabilidad y/o ambigüedad enunciativa es la que da paso y abre a la posibilidad de considerar la intervención de "dobles" del sujeto enunciativo, ya que, como se ha señalado, se muestra un desprendimiento que podría dar lugar a la convivencia de distintas voces alternantes interactuando, "estructuradas" como secuencias donde hay silencio y ocultamiento o palabra y revelación (NEGRI, 2014, p. 134).

${ }^{38}$ Tradução minha. Original: entendido como un pacto discursivo en el que se toma dimensión de un sujeto corporal en relación con el entorno que lo rodea y su universo afectivo (Rodríguez, 2009), asume que ese sujeto enunciador no necesariamente responde a un sujeto real, sino que puede surgir como una construcción ficcional de un yo enunciativo en el poema (NEGRI, 2014, p. 131).
} 


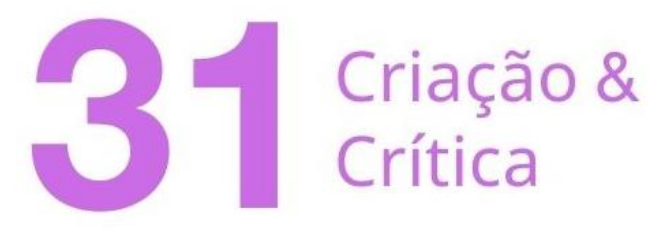

Durante a exploração da voz emergem sonoridades conhecidas, certas musicalidades se repetem, certas memórias sonoras retornam, certos tipos de emissão vocal apreendidos em momentos passados aparecem e se desdobram em novas articulações. Portanto, o conhecido e o desconhecido convivem. Na exploração vocal há uma tensão constante entre aquilo que já foi escutado e habitado pelo corpo, aquilo que está sendo lembrado, e aquilo que emerge na necessidade de outras expressões. A imprevisibilidade e as emissões vocais desconhecidas emergem como novas projeções de um eu lírico em trânsito, desdobramentos do que é entendido como "a minha voz". Na peça vocal Una mirada desde la alcantarilla predomina o contraste entre tipos de emissões vocais e intenções do corpo. Ao se escutar o início da peça, o grave não vozeado, uma espécie de rouquidão ressonante, e logo escutar o grito final vozeado, ingressivo e multifônico, dificilmente reconhecem-se indícios de que essas vozes foram produzidas pelo mesmo corpo. Isto não é algo raro no âmbito da experimentação vocal, já que nesse terreno há uma busca constante pela fricção entre diferentes qualidades vocais, como nos trabalhos de Meredith Monk (Estados Unidos, 1942), Naná Vasconcelos (Brasil, 1944-2016), Demetrio Stratos (Egito/Itália, 1945-1979), Pamela Z (Estados Unidos, 1956), Sainkho Namtchylak (Tuvá, 1957), Tanya Tagaq (Canadá, 1975), Rully Shabara (Indonésia, 1982), Marcela Lucatelli (Brasil, 1988) e Sofia Jernberg (Etiópia/Suécia, 1983).

Uma das questões principais nos estudos sobre a performance vocal desde diferentes perspectivas é o entendimento da produção vocal como uma evidência da elaboração da subjetividade. Na investigação das possibilidades das vozes durante a improvisação, percebe-se que cada pessoa possui uma bagagem sonora e musical, uma série de automatismos, e ao mesmo tempo um campo vocal em constante processo de conhecimento, ligado à tensão e relação social e à experiência de escuta. Essa bagagem pode ser entendida, segundo a teoria de comportamento restaurado estudada por Richard Schechner (2002), como ações que já foram realizadas ou repetidas, "repetição provisória, sempre sujeita à revisão, sempre passível de reinvenção, repetição que nunca se oferece da mesma maneira, mesmo quando sustentada pela constância da transmissão" (MARTINS, 2003). Na perspectiva de Martins (2003), a repetição não seria necessariamente vista como um hábito, mas como uma técnica e uma prática de preservação de saberes, valorizando seus procedimentos de transmissão. Aqui emerge o paradoxo sobre a irrepetibilidade da performance e seus componentes restaurados. Embora haja sempre elementos inscritos no corpo, passíveis de repetição, a partir da memória muscular, simbólica e afetiva, como já foi mencionado, a performance acontece na relação, na maneira como interagem corpos, objetos, vocalidades e gestos.

\section{Performatividade vocal}

Na peça vocal Una mirada desde la alcantarilla, proponho pensar o corpo como um inventário de vozes que se constitui por meio da performatividade e se ressignifica a partir do poema. Não é um inventário estritamente linear, mas uma série de memórias que estão constantemente em erupção. Nele há inscrições que se dão em processos involuntários e voluntários de repetição. A performatividade é conduzida pelas imagens do poema e pelo modo em que este é encarnado no corpo durante a exploração vocal. Uma vez que o poema foi percebido há também um processo que passa pelas contingências do corpo que encarna 


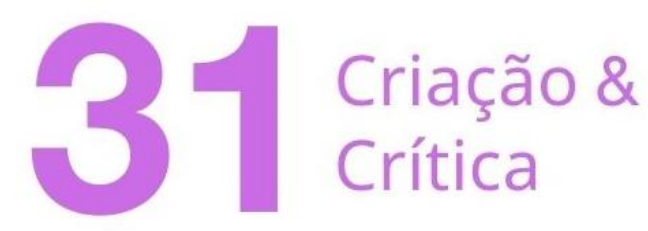

estas imagens. O corpo possui limitações. O poema sugere também seus limites. Se as vozes seguem modos performativos que implicam treinos em ambientes limitantes, há como sugerir formas de expandir esses ambientes por meio de deslocamentos em relação ao modo de respirar, de fonar e de improvisar que propõem uma investigação do desejo. Na exploração vocal podem-se traçar caminhos para elaborar vocalidades percebendo as cristalizações cotidianas, friccionando diferentes escutas. É por meio da expansão da escuta que a performatividade da voz se desdobra. Não se trata de uma expansão coclear, pelo mero ato de "ouvir mais", mas de poder entender a escuta como um modo de refletir. É por meio da escuta que se pensa no que se quer dizer, no corpo. O inventário vocal é constituído não só de palavras, canções, respirações, gritos, choros, gargalhadas, gemidos e tosses, mas também do som do vento no abacateiro, do som de um carro falcon azul que não liga às cinco da manhã por causa do frio, do som de uma mala velha sendo arrastada pelo asfalto, do som da voz de um homem branco falando "vossa senhoria", do som de uma manifestação pela desmilitarização da vida no Brasil, do som de balas de borracha, dos dedos digitando no teclado com peças deslocadas, de um trovão que chacoalha o vidro, do canto de uma araponga no falante do celular ou de uma maritaca na avenida Ricardo Jafet, do gemido da geladeira, da lavadora velha que anda pela casa, do relógio analógico. O inventário de vozes não é aleatório ou destituído de sentidos, são marcas físicas ligadas à memória; trata-se da história de escuta de cada corpo que transparece uma série de contextos, neste caso, por mim habitados.

A performatividade, nos diz Schechner, é ao mesmo tempo uma ferramenta teórica, e um ponto de vista analítico orientado. Se toda realidade, objeto, acontecimento ou ação podem ser vistos do ponto de vista da performance (as performance), isso significa que como performance, há, portanto, performatividade em todas as coisas (FÉRAL, 2009, p.65).

A noção de performatividade tornou-se extremamente relevante para as teorias pósestruturalistas que tensionam perspectivas universalizantes, originais e binárias. Segundo o teórico dos estudos da performance Richard Schechner (2002), a performance sempre remete a uma relação. Nesse sentido, a unicidade do evento não depende unicamente da sua materialidade, mas também das interações que acontecem a partir deste evento. O linguista Austin (1990) qualifica os enunciados vocais/verbais como performativos, ao atribuir nestes uma forma de ação, como por exemplo: "os declaro marido e mulher" ou "sim, juro". "O termo performativo deriva do verbo perform [...]; ele indica que o produto de uma enunciação é a performance de uma ação. O uso das palavras, portanto, é tido como, ou o mesmo que, a principal ocorrência na performance do ato [...]" (FÉRAL, 2009). A fala não indica, mas faz. Féral (2009) entende que a teoria de Austin é incompleta por precisar de uma situação específica ou contextos definíveis para o enunciado se tornar uma ação. Isto faz com que "o risco e o fracasso do enunciado se tornem constitutivos da performatividade" (FÉRAL, 2009). Segundo Féral (2009), o fracasso torna-se um direito. Embora a ação não seja concretizada, o enunciado produz uma situação. Derrida expande esse entendimento para além da linguística, "na medida em que, para ele, todos os códigos humanos e expressões culturais são escritos, então a performatividade em si é escrita” (FÉRAL, 2009). A partir do momento 


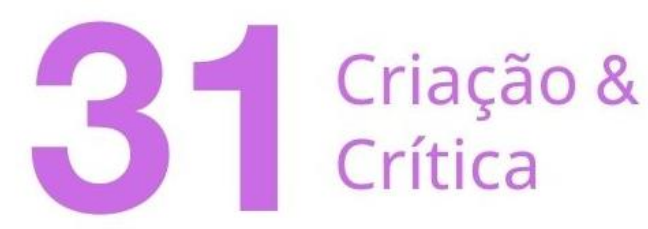

em que um enunciado é pronunciado há algo sendo feito, assim como o corpo, do modo em que se apresenta, inscreve e escreve algo no ambiente. "O conceito de performatividade pode, portanto, aplicar-se não só a toda ação, mas também às disciplinas que geralmente não entram no campo da performance: a arquitetura, a literatura, o direito, a pintura, etc" (FÉRAL, 2009).

Judith Butler aprofunda o conceito de performatividade no seu livro "Problemas de Gênero" (2003), ao criar uma genealogia da produção feminista da categoria mulher. Esse caminho leva a autora a investigar a origem do problema, que seria, a produção da identidade. A pesquisa genealógica não busca uma verdade ontológica, mas propõe uma construção contingente e descontínua. Segundo a autora, "Gêneros 'inteligíveis' são aqueles que, em certo sentido, instituem e mantêm relações de coerência e continuidade entre sexo, gênero, prática sexual e desejo" (BUTLER, 2003). Frente a essa realidade, Butler propõe uma compreensão fluida, performativa e não fundacional, de gênero e sexualidade, e critica a concepção de gênero como algo pré discursivo. "As performances, artísticas, rituais ou da vida ordinária - são feitas de comportamentos duplamente feitos, comportamentos restaurados, ações performadas que as pessoas treinam para executar, que praticam e ensaiam" (FÉRAL, 2009). Se os corpos sofrem processos de adequação por meio da performatividade, que é, em resumo, a reprodução de uma série de ações e comportamentos promovidos, por exemplo no contexto da família nuclear, das religiões, da escolarização, e de uma série de instituições que afirmam representar esses corpos, mas que igualmente os produzem, as suas vozes fazem parte também desses pactos.

Durante a exploração vocal, as vozes, mesmo quando não pronunciam palavras ou discursos dentro de um campo semântico pré-definido, realizam inscrições no corpo. As vozes respondem a sistemas de escrita que determinam certos comportamentos e expressões, não só no que se refere às classificações vocais cristalizadas no campo da música, mas também ao modo de falar, à suavidade esperada de alguns corpos, à firmeza esperada de outros, à predominância da linguagem verbal como veículo de informação e como produção de verdade, e ao entendimento da voz como veículo das palavras em detrimento do seus aspectos físicos. Todos esses aspectos são lidos de maneiras específicas em diferentes contextos. Se a visão de corpo é entendida a partir de certos códigos, normas e ficções, ligadas às noções de sexo e de gênero, de raça e de classe social, às suas funções reprodutivas e consumidoras, por consequência, também a escuta de vozes é devastada por essas normas e códigos. As vozes ressoam também ligadas a esses sistemas. As inscrições sociais do corpo em performance criam uma determinada expectativa das possibilidades vocais. É nessa perspectiva que o conceito de performativo se ergue nas discussões sobre vocalidade. A exploração vocal é um processo de busca e de exercício do prazer pelo conhecimento das possibilidades da voz que se encontram, de modos diferentes, atreladas às classificações e interpretações ligadas às diferentes experiências da corporeidade e suas marcas. Esse conhecimento passa por questionamentos constantes em relação aos processos de auto definição frente às categorias institucionalizadas, categorias não só de local social, mas também no que se refere aos diferentes campos das artes.

O que a filósofa Adriana Cavarero (2011) chama de unicidade vocal é constituído por uma série de fatores que situam as vozes em um contexto específico, delimitado por questões políticas, sociais e institucionais. Não há uma unicidade vocal essencial. Embora haja uma estrutura física única, as vozes se alimentam continuamente de padrões, por meio da aquisição de uma linguagem verbal, na influência dos contextos sonoros (país, cidade, bairro) 


\section{Criação \&}

habitados por quem vocaliza que determinam diferentes comportamentos vocais. Ao mesmo tempo, o eu se multiplica na voz que experimenta e transita entre as suas possibilidades e escutas. A unicidade pressupõe aqui também pluralidade, uma vez que a exploração vocal implica sempre em reciprocidade e relação, e ao mesmo tempo na expansão do corpo por meio da escuta como ignição para diferentes vocalidades. "No entanto, a unicidade é definida por uma fisicalidade, uma escuta e uma história específica, resultando em sonoridades próprias de uma corporeidade irrepetível" (BRANDES, 2019).

\section{Considerações do fim ao início}

Além da junção de temporalidades que são propostas no poema por meio do duplo literário, o ato da leitura leva a atenção para o corpo de maneira imediata, em um cruzamento de espaço-tempo, entre lugares do texto e o local onde o corpo que lê se encontra. Neste sentido, a leitura é também um umbral, algo entre dois cosmos, uma espécie de vácuo. $\mathrm{E}$, ao mesmo tempo, ela é também um conhecimento que se dá pela corporalidade, pelo toque, pelo olhar e pela escuta, pelos seus efeitos na corrente sanguínea e na respiração. "A palavra alude às vísceras, ao corpo profundo onde fervem os humores das paixões" (CAVARERO, 2011).

O poema número 23 de Alejandra Pizarnik induz quem lê a se situar e a buscar algo. De quem é esta mirada e que visão do mundo possui? Una mirada desde la alcantarilla como poema, e o livro "Árvore de Diana" como um todo provocam na minha prática vocal uma ação de deslocamento, direcionando a escuta interna para questões da leitura do corpo que são muito pertinentes em relação à investigação da voz. Há na ideia de restauração e fragmentação do corpo uma potência para a composição que radica na necessidade de transformação, não só pela ação de ir de um lugar para o outro, mas pela vontade de perceber aquelas mudanças de um corpo que saiu do lugar de origem faz onze anos e que já não fala a mesma língua, na hora de desdobrar o eu lírico, na hora de abordar o campo experimental da máquina performática, e na hora de escrever sobre esse processo. Aqui se misturam escritas apreendidas no âmbito musical e intenções de um pensamento de corpo. $O$ pensamento de corpo surge da interpretação cênica do poema. "A escrita cênica já não é hierárquica e ordenada; ela é desconstruída e caótica, ela introduz o evento, ela reconhece o risco" (FÉRAL, 2009).

Aquilo que no início se apresenta como uma visão possível desde o subterrâneo, na passagem do tempo, ou ao atravessar certa continuidade e insistência, se desfaz totalmente. Pizarnik propõe um olhar insistente como um ato de rebeldia, como possibilidade de existência, e é através dele que surgem significados, para quem lê. Neste poema, é como se só o final nos fosse dado, e tudo o resto precisa ser criado. Portanto, para encontrar essa sonoridade final é necessário passar por tudo aquilo que não foi explicitamente colocado, como se o poema em si fosse um resultado inconcluso de uma vivência indescritível, preferivelmente não nomeada. Nesse sentido, o processo de composição precisa passar por uma pesquisa de sons que no seu desenvolvimento leve a "pulverizar os olhos" e os ouvidos. Sei que no final haverá uma grande explosão, a partir da qual aquilo que parece uma única voz, finalmente se multiplica, mostrando que uma voz carrega sempre outras vozes. Não sei ainda como será essa grande explosão. Para isto preciso voltar ao início. Começo então pela perspectiva do olhar, e busco onde ela ressoa no corpo. Sei que se trata de uma ficção, de uma invenção a partir do que reconheço como bueiro, como subterrâneo, principalmente nas 


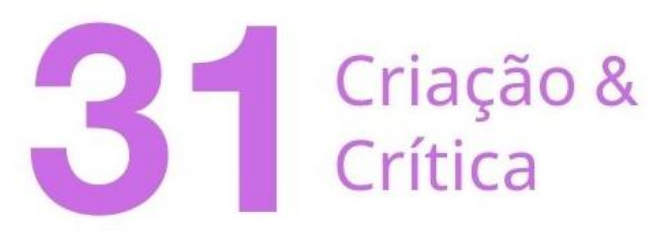

cidades onde morei: Buenos Aires, Campinas e São Paulo. Mas também sei que aquelas paisagens sugeridas por Pizarnik não são silenciosas. Procuro o bueiro nos espaços internos da boca. Ressoa no peito, no pescoço e na nuca.

\section{Referências bibliográficas}

AGUILAR;CÁMARA, Gonzalo \& Mário. La máquina performática. Buenos Aires: Editora Grumo, 2019.

BARBERO; PAMPÍN, Ayelén e Ludmila. "Figuraciones de la corporalidad en Extracción de la piedra de locura de Alejandra Pizarnik". Pádua: Editora Padova University Press. Revista Orillas, 4, 2015.

BRANDES, IT. Entre Vozes Viajantes: Exploração Vocal no Teatro Invisível de Meredith Monk. Dissertação apresentada na Escola de Comunicações e Artes da Universidade de São Paulo. 2019.

BUTLER, Judith. Problemas de Gênero. Rio de Janeiro: Civilização Brasileira, 2003.

CAVARERO, Adriana. Vozes Plurais: Filosofia da Expressão Vocal. Belo Horizonte: Editora UFMG, 2011.

FÉRAL, Jossette. Performance e Performatividade. Performance e performatividade. Tradução: Edélcio Mostaço e Cláudia Sachs. In: Sobre Performatividade - Grupo de Estudos Inter-textos, p.49-86. Florianópolis: UDESC, 2009.

GABRIELONI, Ana Lía. Imagen y visualidad en la última poética de Alejandra Pizarnik: el vacío vocativo. Université de Lausanne; Boletín Hispánico Helvético; 21; 6-2013; 247-263.

MARTINS, Leda. Performances de oralitura: corpo, lugar de memória. Letras no 26. Língua e Literatura. Belo Horizonte: Limites e Fronteiras, 2003.

NEGRI, Matilde Belén Escobar. Sobre la enunciación poética y el doble: una aproximación a la poesía de Alejandra Pizarnik. Tunja: La palabra No. 26, pp. 129-136. 2011.

PIZARNIK, Alejandra. Árbol de Diana. Publicaciones Paradoja, (2003 [1962]).

PIZARNIK, Alejandra. Árvore de Diana. Tradução de Davis Diniz. Belo Horizonte: Editora Relicário, 2018.

RIZZI, Nina. Árvore de Diana. Edição Ellenismos, 2017.

SCHECHNER, Richard. Performance Studies. Routledge.2002.

TORRES, Fernando Salazar. "Árbol de Diana, ausencia y pérdida de Alejandra Pizarnik". Revista Máquina. 21 de março, 2017. Disponível em: < Árbol de Diana, ausencia y pérdida de Alejandra Pizarnik>.

ZUMTHOR, Paul. Percepção, Recepção e Leitura. São Paulo: Cosacnaify Portátil 27, 2014. 


\section{1 criaçäo \&}

Entrevista com Davis Diniz no site uai.com,br. Disponível em: <Editora lança pela primeira vez no Brasil a tradução de Árvore de Diana e Os trabalhos e as noites, da argentina Alejandra Pizarnik >. Acesso em 07 out 2021.

Recebido em: 24/08/2021

Aceito em: 28/11/2021

Referência eletrônica: BRANDES, Inés Terra. Una mirada desde la alcantarilla: uma versão vocal do poema homônimo de Alejandra Pizarnik. Criação \& Crítica, n. 31, p., dez. 2021. Disponível em: <http://revistas.usp.br/criacaoecritica>. Acesso em: dd mmm. aaaa. 